\title{
UM RELATO DA EXPERIÊNCIA DA UTILIZAÇÃO DA TÉCNICA OCC-RDD EM UM DO CURSO DE COMPUTAÇÃO
}

\author{
Karina Buttignon ${ }^{1}$ \\ Ítalo Santigo Vega²
}

Resumo: Este artigo tem como objetivo relatar uma experiência didática, da utilização da técnica OCC$R D D$ (Objetivo, Contratempo, Catástrofe, Reação, Dilema e Decisão) em um curso de computação. A técnica OCC-RDD foi criado no GEMS (Grupo de Estudo de Modelagem de Software) PUC-SP e define uma nova abordagem de ensino, especificamente para o curso de computação, propondo a utilização de narrativas dentro da disciplina e que possam auxiliar o aprendiz na resolução dos exercícios propostos em sala, a técnica propõe uma metodologia que pudessem apoiar o professor e o aluno, levando-os a uma experimentação mais interativa quanto ao ensino no curso de computação. Para organizar a leitura de uma forma sucinta este artigo irá descrever a técnica OCC-RDD na introdução e em seguida apresenta a metodologia, os resultados computados a partir da aplicação da técnica, a discussão apresentando um modelo de aula OCC-RDD e finalmente as conclusões deste relato.

Palavras-chave: Computação; Ensino; Fábula; Narrativa.

\footnotetext{
${ }^{1}$ Computação/Fatec Guaratinguetá, Brasil. E-mail: karina.buttignon@gmail.com.

2 Computação/Pontifícia Universidade Católica de São Paulo, Brasil. E-mail: italo@pucsp.br.
} 